\title{
Twain: And the Relation Between \\ What We Make and \\ What We Do Not Make
}

\section{Louise Gendreau}

The King's College, Edmonton

A feature of The Adventures of Huckleberry Finn is Twain's anticipation of a response to his book. He writes in a way which anticipates a reply from his readers. He uses his awareness of how they will interpret him to recommend how readers ought to read. Although it appears that another's interpretation cannot be made, Twain shows that another's interpretation is within the realm of what a writer makes. He prefaces Huckleberry Finn with the following explanatory notes:

In this book a number of dialects are used, to wit: the Missouri Negro dialect; the extreme form of the backwoods Southwestern dialect; the ordinary "Pike County" dialect; and four modified varieties of this last. The shading have not been done in a haphazard fashion or by guesswork; but pains-takingly, and with trustworthy guidance and support of personal familiarity with these several forms of speech.

I make this explanation for the reason that without it many readers would suppose that all these characters were trying to talk alike and not succeeding. ${ }^{1}$

Twain begins his book by alerting his readers that, contrary to their interpretation of fiction as "guesswork" or as work "done in a haphazard fashion," it is grounded in "personal familiarity." He knows the reader's tendency to assume that fiction is whimsical. To Twain, writing is not a matter of exercising our fancy, it is guided by something other than sheer fabrication. Twain formulates writing as both guided and decisive in character. So a writer cannot write just anything, as if writing was a self-inspired activity. Rather, Twain suggests that "personal familiarity" informs his writing with a sense of reality. What does this mean? Perhaps Twain means that nonaccidental writing is writing which is made necessary by virtue of what it is inspired by. This paper seeks to understand what this could mean by inquiring into the relation between what we as writers make and what we cannot make.

It must be noted that Twain prefaces Huckleberry Finn, an adventure novel, with a reminder of its decisive character, alerting his readers to the fact that it is not arbitrary. Twain knows that the suggestion that writing is guided will be interpreted in a certain way. The concern for what guides writing will be treated by his readers as 
searching for the motive of a text, which would be to search for the cause of writing. Twain is against treating a concern for what guides writing as a concern for providing the reasons for writing. He says in the preface: "Persons attempting to find a motive in this narrative will be prosecuted; persons attempting to find a moral in it will be banished; persons attempting to find a plot in it will be shot" (p. xi).

Why is Twain against his readers finding a motive, moral, or plot in Huckleberry Finn? To suggest that a motive, moral, or plot could guide a writer in his or her writing is to suggest that he or she is guided by what he or she can make. And yet perhaps what really guides us is something we cannot make: what is truly Other. Twain's claim not to produce work which has a motive does not mean that he is not motivated; rather it means that what is truly moving is not produced. It is something we do not make. What is the relation between writing (what we make) and what inspires our writing (what we do not make)?

Twain's preface is inspired by the recognition of corruption. His readers personify the possibility of corruption with the resignation of their opinion. I argue that this corruption manifests itself in the impulse to treat difference as the same. That is, insofar as readers approach his work with the concern for motive, moral, and plot, they look to what could guide writing as what human beings make. Corruption, then, is reflected in possessiveness; that humans possess what inspires them.

I would like to return to Twain's preface as a way of understanding how corruption is reflected in a possessive relation to the world. Recall that Twain is against the reader finding a motive, moral, or plot in his book. Why is this? To be concerned with the plot of a story is to be concerned with the pattern of events around which the story develops. This requires a clear idea of what happens before beginning to write. To begin with a clear idea of one's story is to be able to control the writing. As long as one keeps plot in mind, the writing cannot get out of hand. Plot construction assures the writer of being in control by ensuring that the story arrives somewhere.

Why is Twain so against our looking for a plot to his story, especially when a plot suggests that the story has not been written in a "haphazard fashion or by guesswork"? What does Twain want when he wants his readers to recognize the decisive character of Huck Finn? He does not want his readers to look for the plot, although it is responsible for ordering the events of a story. Inspired writing is more than ordered writing and so is not ruled by plot construction. Twain himself admits that he usually began his work with no clear idea of his story in mind. Writing, in Twain's opinion, cannot be forced by the writer. So, although looking for the plot may recognize that the story is not arbitrary, it is concerned for what forces the story. To be concerned with what forces a story is not the same as a concern for the story's force. To look to Huck Finn's forcefulness would require 
feeling addressed by our reading of the story. It would require being present so as to have an opinion.

It is not accidental that Twain says, "persons attempting to find a plot in it [Huckleberry Finn] will be shot." Perhaps he is saying that those who look for the plan of Huckleberry Finn are really shooting themselves. To shoot is to cause to be driven forward with force. It is to discharge, setting off an explosive charge which could possibly destroy. To look for a plot, or be concerned with what forces a story, is to discharge one's opinion for the sake of the author's plan. A concern for plot could be self-destructive insofar as it takes no interest in self or self's relation to what it confronts such as a book or tradition. As for the writer, to discharge much for the sake of what can be planned out (the plot) is a real crime, because one is not open to what can be truly influential in one's writing. Writing as an activity under our control reflects a certain corruption, one where the writer is seen as in possession of what inspires him or her.

Likewise, to look for the moral in Huckleberry Finn would involve treating Twain as one who knows the lesson to be learned from the story. To look for a passage which points out the lesson to be learned is to treat the writer as self-reliant, as if learning did not require the reader's participation. So in any reading of Huckleberry Finn the writer becomes one who possesses the knowledge of what is to be learned. Twain is against this treatment because such a concern results in banishment. As he says in his preface, "persons attempting to find a moral in it will be banished" (p. xi). Banishment is the requirement to leave one's home, which resonates with being dismissed because of an unwanted influence. To look for a passage which points out the lesson to be learned is to banish one's own opinion. The reader dismisses his or her opinion for the sake of the moral of the story. This dismissal does away with the reader's involvement thereby treating his or her particularity as an unwanted influence. Consequently, the version of what is to be learned requires denying history as important in arriving at the lesson.

It is imaginable that a concern for the moral of Huckleberry Finn is a concern which recognizes the story's intentional character. The story has a point and is therefore not written in a "haphazard fashion or by guesswork." But the recognition of its nonaccidental character does not make the writing of Huckleberry Finn decisive or inspired. Similarly, a concern for the story's motive appears as a concern for why Twain would write what he did and not something else, which resonates with its other than accidental character. And we know that Twain wants his readers to recognize that the story has not been written in a "haphazard fashion or by guesswork; but pain-stakingly, and with trustworthy guidance and support of personal familiarity" (p.xi).

A feature of "haphazard" writing is its whimsical character, which is marked by the lack of plan, order, or direction. If Twain is against 
haphazard writing because it is undirectional, then common sense suggests that we could expect him to argue for writing which is planned, orderly, and directional. Yet we see that Twain warns his readers against looking for a motive, moral, or plot in Huckleberry Finn, all of which produce orderly writing. His warning originates in his dissatisfaction with treating the writer as one who possesses what inspires him or her. In other words, writing which is planned, orderly, and directional is still not oriented writing: writing oriented to what is inspiring. For example, let us return to Twain's warning that "persons attempting to find a motive in this narrative will be prosecuted" (p. xi). To warn against looking for a motive in a story is not to suggest that the story is aimless and nonoriented. Rather, what the story aims at or orients to cannot be produced. Twain's writing is given aim by what inspires his writing.

Readers who are concerned for finding the motive in the story are really prosecuting themselves. If a concern for motive is a concern for the reasonableness of the story, then this is a concern for accusations. How can readers treat themselves as the accused by looking for the motive of Huckleberry Finn? To look for the motive is to assign relevance to Huckleberry Finn in a way which recognizes it as appropriate or inappropriate. Motive then becomes the judge of what is acceptable, creating a passive reader. The reader violates himself or herself insofar as he or she looks to Huck Finn's motive as what determines meaning. The impulse to seek a motive of a story is the impulse to determine a story's intention, so that the reader can feel if he or she is on the right track. Ironically, to search for the right track, by seeking a story's motive, is to search for the right track as what does not belong to us. The concern for motive constructs the notion of right track as one we do not make. In this sense, we corrupt what is ours by denying ourselves what we can make and in so doing treat the author as the sole determiner of what can be made. This suggests that the author is self-reliant in his or her writing; that he or she need not orient to anything other than his or her fancy. Twain is opposed to the reader denying his or her opinion for the sake of the writer's opinion. Twain makes no claim that his opinion is what readers ought to orient to.

Twain's dissatisfaction with the readers' concern for motive, moral, and plot was occasioned by their denying their opinion for the sake of the author's; hence it was occasioned by a concern for their singularity of opinion. The concern for the singularity of opinion reflects a concern for the "clear" idea, for what Huckleberry Finn is "clearly" about. A clear idea, in contrast to a confused idea, does not allow itself to be interpreted by any other idea. ${ }^{2}$ It wishes to remain decisively itself, unpolluted by anything but itself and its own resulting clarity. The clear idea has precise and limited boundaries. It wishes to spare itself the effort of thought that is involved in relating itself to other ideas. This concern for the clear idea treats different ideas 
as enemies rather than as friends. In other words, any kind of interpretation other than that of the writers, is treated as an act of invasion. Insofar as one alters what is clear, one corrupts it. And what is clear is what the writer (Twain) gives us, which in this case takes the form of motive, moral, and plot of Huckleberry Finn. Readers are fascinated by the power of the clear idea, because their energies become clearly directed.

Twain knows that readers have a tendency to become one with what they read. This singularity of opinion is accomplished through the readers' concern for the story's motive, moral, and plot. We have seen how this concern creates a singularity of opinion insofar as the reader denies his or her opinion for the sake of the author's. More deeply, to feel we cannot resist what we have been given results in treating what we have been given as self-sufficient. Here this involves treating Huckleberry Finn as if the story were not in need of particular readers; that the best we can do as readers is to reproduce the story, repeating what the author intended.

Reproduction and review are forms of reading and writing which submit to the power of the clear idea. Their submission can be understood in light of the recognition that all interpretation strives for clarity of insight and comprehension. But we must not forget that clarity is what the interpretive process seeks to accomplish. Clarity is a standard imposed on any activity which seeks meaning. And as a standard clarity, it is what we orient to in our writing. It is not to be confused with the outcome of our interpretation.

One understanding of the importance of interpretive procedures for uncovering the meaning of a text is embodied in a concern for the motive, moral, or plot of a story. We have discussed how a reader's concern for the story's motive, moral, or plot produces what we have called singularity of opinion. Singularity of opinion is achieved by assuming that the interpretation of meaning is located in the author's intention. The interpretive process can grasp meaning only by submitting to the author's intention, only by collapsing the difference between intention and meaning.

Writing which collapses the differences between intention and meaning is writing that takes the form of review and reproduction. A review looks over what we make in light of what we do not make (a standard). The ability to review one's action depends on the recognition of what is right. A review is mindful of a standard to which it orients. The recognition that one could appear opposed to what we would want to stand for makes a review possible. So long as we remember that we live in order to preserve something, we are able to review our actions. What is essential to a review then is the memory of what it seeks to preserve.

How does a review care for what it seeks to preserve, the standard? We would want to ask how the standard necessitates a review. In the face of corruption, the reviewer could feel duty-bound or defend 
what he or she values, the standard. This feeling of obligation means that he or she is indebted to the standard, and that action vis-à-vis the standard is dutiful. Hence a review will subordinate everything including itself to the standard. A review seems to be obliged to the standard rather than enjoying its influence. Obligation becomes its way of caring for what it seeks to preserve. Obligation as a relation to what we do not produce is complacent about what is significant, because everything becomes subordinated to the standard. One shows appreciation of the standard by accepting it. Mere acceptance implies a nonproductive relation to the standard. In contrast, an interest in reproduction seeks a productive relation to the standard and an active relation to significance.

An interest in reproduction is convinced that a standard should be enjoyable, and is therefore concerned for its reproduction. Writers show their use of what they do not make by reproducing it, by treating the standard as what can be produced. The standard holds the writer insofar as he or she is convinced of its enjoyable influence. In seeking to produce what he or she does not make-the standard-the writer takes pleasure in his or her powers of production. Enjoyment, unlike obligation, is a reproductive relation to the standard.

Reproduction is not reluctant to affirm what it knows to be enjoyable. In its enthusiasm for what it knows (that the standard should be enjoyable) it subordinates the standard to itself. This means that there is no respect for what is other than self, because the self thinks it is responsible for everything. Reproduction fails to transform what it started with, because it subordinates other to self. Reproduction, then, collapses what it does not make into what it does make for the sake of determining its own powers.

A literal reading is a form of reading which is passionate about reproduction. When a particular adventure novel does not provide pleasure, a literal reading abandons it. Understanding is then freed as something which externally "happens" to us. A real interest in understanding would treat it as internal. This means that the meaning of a novel would point to our involvement with the book. Instead of abandoning its activity when it doesn't promise enjoyment, a literal reading has an opportunity to show how what it knows (that understanding is enjoyable) has a hold on the reader, rather than treating what he or she knows preferentially. Instead of abandoning the book, how could a literal reading begin to revise it, or is reproduction the best a literal reading could do?

When we think of revising a book, we think of asking ourselves what is really important in the book such that we need to preserve its sense of importance? What is important requires not only preservation; it also requires our embodiment. And it is in our treatment of the book that we show our effort at attaching ourselves to what we are given. 
How do we go about attaching ourselves? Recall that a review would suggest subordinating itself for the sake of what it wants to preserve. This however, was not an enjoyable relation to the book because alteration could only be interpreted as doing an injustice to what has been given. On the other hand, reproduction would take pleasure in reproducing the book to the point of assimilating itself to what it has been given. Reproduction, then, forgets what we start with and it remembers that we make a difference; it remembers what we cannot make, as well as what we do make.

Revision resists what we do not make in a just way by appreciating what it does not make. This appreciation can be seen in making a difference. For example, revision shows an initiative which is not afraid of altering what it is given. It is not afraid because it wants to actively participate in realizing what we do not make, the standard, which requires resisting it. A vision informs the revision such that it could realize what it started with. Revision always remembers that it is not first by showing its relation to what is first: the standard or the tradition. Unlike a review, this relation is not one of obligation, but one of realization. Recall how review denied itself for the sake of what it sought to preserve. Revision makes itself necessary by treating as significant what it is given and not as given. This is to say that what is given can be engaged in the search for its significance. And the significance and meaning is arrived at through a process of engagement. What does this mean?

It may help to recall Twain's preface where he alerts his reader to the dangers of looking for motive, moral, and plot in his book. We could now hear Twain as suggesting that the significance and meaning of his book will not be found by looking for what the author controls, but rather by attempting to engage what is given, what we do not produce. Twain's dissatisfaction seems to lie with the assumption that what an author produces is responsible for the significance of the writing, as if significance is solely a matter of production. To consider Twain's claim that writing is undirected yet oriented seems to point to an understanding of the nature of writing in which significance is set by the author as well as by what the author does not make. In other words, we might say that direction is set not only by a driver but also by the passage. Perhaps this is what Twain means by his warning not to look for the motive, moral, or plot of Huckleberry Finn, and by his reminder that the book is not "haphazardly" written. Writing can lack direction yet be oriented, if we think about the necessity of engaging what we have been given, if we think about revision.

We have seen how both review and reproduction seek a relationship to what they have been given, but that both tend to be complacent about their relationship. For review, direction is set by the passage, whereas for reproduction direction is established by the driver. To have one's direction set by the passage is to be led by circumstance. 
Here, the self shows no initiative in leading oneself. On the other hand, for direction to be established solely by the driver, the self, would mean leading without a sense of being led; without a sense of what guides one's initiative. To put this another way, we would say that review doesn't own up to itself, as it is too concerned for preserving what it does not make. Writing is being led, as if an "I" didn't produce it. This could result in writing which Twain calls "haphazardly" done, work which is moved by external circumstances. We could say that reproduction becomes so concerned for what it makes that writing is treated as unalterable. Here writing is directed as if the "I" was solely responsible for producing it. Twain has an understanding of the nature of writing in which the writer seeks to realize what he or she did not produce, by taking responsibility for what he or she does produce. This concept of writing we call revision.

Revision resists the extremes of review (subordinating self to other) and reproduction (subordinating other to self). How does revision transform the excesses of thinking that self is responsible for all that is other (reproduction), and that self is responsible for no other (review)? We can see how revision is a transformed version of reproduction and review by inquiring into the sort of practice revision is. Revision is the sort of writing which seeks to act in such way that it shows itself, while respecting what is other to the self. It displays what review lacks: the knowledge that self can make a difference. And it displays what reproduction lacks: the knowledge that other can make a difference. Self is not identified with other, so as to either deny self (review) or deny other (reproduction). Revision is an idea of writing which does not lack orientation.

What sort of writing movement is revision? Is it a movement in which we are pulled in different directions? To be pulled in different directions suggests confusion and disorientation. This would not make Twain's claim necessary that Huckleberry Finn is not done in a "haphazard fashion or by guesswork," how it is written with a motive, moral, or a plot in mind. The alternate version conceives of writing as concerned with "clarity." Recall that Twain's readers tend to be concerned with the clear idea in Huckleberry Finn, in other words, with what Twain produced. In this sense orientation was no different than direction. It meant that writing had direction because the writer would establish his plan in advance. And writing was assured of arriving somewhere. This also does not make understandable Twain's claim that writing is oriented but without direction.

In Huckleberry Finn Twain shows us how we can be moved by what we really don't understand. This resonates with a movement which is without direction, yet is oriented. To suggest that we can be moved by what we do not understand is to suggest that we cannot determine where we will end up. We cannot determine where we end up, not because we want to go in different directions at once, but because we are guided by what we cannot direct. 
Writing which may not get anywhere, yet does not stand still, is writing which suggests a revisionary character. When I think of revision, I think of how it is possible to say that the writing is both the same and different. A reviser alters his or her first piece in order to improve it. This alteration is friendly toward what it began with. To be able to say that writing is both the same and different is to recognize that what is the same endures through many alterations. This makes it possible to treat the end as a beginning, because the concern is always the same. Writing which treats an end as a beginning suggests movement without direction, yet movement which is oriented. The movement which displays orientation is the movement which takes other into account: it is the movement which recognizes both the place of self and other. How does revision produce a sense of being oriented? The very recognition that what we make must have a relation to what we do not make provides the bearing necessary for orientation. But how can we understand this orientation so as to uncover the relation between what we make and what we cannot make?

The idea of adventure offers us a particular understanding of orientation. In trying to flesh out this idea of adventure, we might consider how Twain characterizes that which falls short of adventure. For instance, consider Twain's characterization of Huck. Huck lets situations control him and appears to subordinate himself to what he confronts. He can accomplish this subordination by divorcing self from other, from history. In this way, Huck fails to see himself as engaging his environment. $\mathrm{He}$ accepts what he does not make as a limit rather than engaging it. Adventure, on the other hand, takes what it does not make as an invitation for involvement. So much relates to writing in the sense of review.

Nor does Tom Sawyer reflect Twain's version of adventure. Tom acts out his urges and appears to subordinate himself. He can accomplish this subordination by assimilating self with other. In this way Tom fails to engage anything other than his powers. He accepts what he makes as a limit rather than engaging it. Tom relates to writing in the sense of production.

Now in terms of the relationship between self and other,, adventure cannot be understood as the attempt of self to dominate other for that would be to reproduce self rather than to engage it. Adventure does not understand itself as dominating what it confronts, what it does not make. Adventure now begins to show its character as an act of engagement with what it confronts.

When we think of the orientation that is adventure, we think of the interweaving of activity and passivity. For instance, the adventurer has the feature of the conqueror, one who is venturesome, enterprising, and resourceful regardless of the relation between self and the world. On the other hand, in adventure we give ourselves over to the world with fewer defenses and reserves than in other experiences. 
Adventure then brings together the idea of the conqueror, who abandons himself or herself to the powers of what he or she confronts. In other words, what we make and what we do not make are brought together. What we do not make is encountered in a way which presupposes that it is knowable. So, although in an adventure we know the difference between what we make and what we do not make, there is also togetherness. The adventurer treats what he or she confronts as holding adventure. What does this mean? Perhaps it means that there is something appealing in an enterprise which involves the unknown, that the excitement of the adventure is the excitement of the unknown which is sought for its own sake, regardless of outcome. The unknown is then seen as disclosive, rather than as self-revealing. To say that something is disclosive is already to suggest that we are taken with it. If what we do not make is seen as disclosive, then it also allows us to see how we are taken by it. For the unknown to be disclosive, it requires our participation in seeing what it discloses.

Now we can return to Twain's preface with a sense of the relation between what he makes (writing) and what he does not make (what inspires his writing). The fact that Huckleberry Finn is an adventure novel has become significant. Twain is aware of how adventure, insofar as it finds the unknown exciting, could risk the appearance of "haphazard" writing. And he is also aware that the writing could take on the character of a conqueror conquering the unknown. But insofar as he risks such appearances, we learn something about the character of adventure. Adventure ventures forth, all the time being grounded in what Twain calls "personal familiarity." This is to say that adventure is not a matter of our whim, nor is it a matter of submitting to what we cannot control; rather it shows itself as orientation to the relation between what we make and what we do not make.

Finally, I would like to suggest that adventure characterizes Twain's involvement with the contents of his writing. This is to say that he treats what he makes, his writing, as containing an element of what he does not make. Such a treatment allows Twain to reexperience what he does make in a changed form: as revision. Revision then cannot be divorced from the experience of adventure. It is, therefore, a necessary feature in writing the adventure novel Huckleberry Finn.

\section{Notes}

1. Huckleberry Finn (New York: Macmillan, 1968), preface. All subsequent references to this are from this edition.

2. I am relying on the Cartesian understanding of clarity. For further discussion see Descartes' Discourse on method. 


\section{References}

Descartes, R. (1960). Discourse on method (L.J. Lafleur, Trans.). New York:

Bobbs-Merrill. (Original work published 1637)

Twain, M. (1968). The Adventures of Huckleberry Finn. New York: Macmillan. 